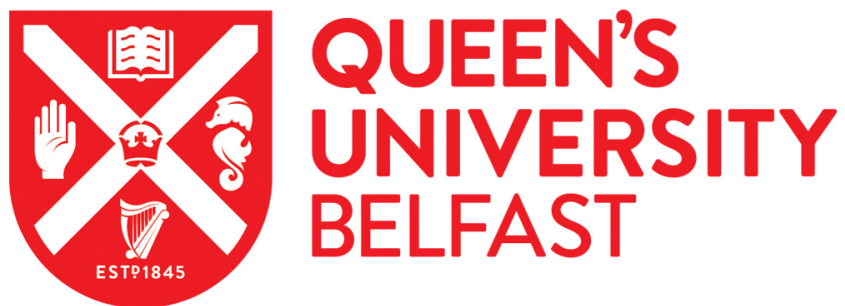

\section{An exploration of whether mental health nurses practice in accordance with The Family Model}

Grant, A., Falkov, A., Reupert, A., Maybery, D., \& Goodyear, M. (2020). An exploration of whether mental health nurses practice in accordance with The Family Model. Archives of Psychiatric Nursing.

https://doi.org/10.1016/j.apnu.2020.04.003

Published in:

Archives of Psychiatric Nursing

Document Version:

Peer reviewed version

Queen's University Belfast - Research Portal:

Link to publication record in Queen's University Belfast Research Portal

\section{Publisher rights}

Copyright 2020 Elsevier.

This manuscript is distributed under a Creative Commons Attribution-NonCommercial-NoDerivs License

(https://creativecommons.org/licenses/by-nc-nd/4.0/), which permits distribution and reproduction for non-commercial purposes, provided the author and source are cited.

\section{General rights}

Copyright for the publications made accessible via the Queen's University Belfast Research Portal is retained by the author(s) and / or other copyright owners and it is a condition of accessing these publications that users recognise and abide by the legal requirements associated with these rights.

Take down policy

The Research Portal is Queen's institutional repository that provides access to Queen's research output. Every effort has been made to ensure that content in the Research Portal does not infringe any person's rights, or applicable UK laws. If you discover content in the Research Portal that you believe breaches copyright or violates any law, please contact openaccess@qub.ac.uk. 


\title{
An exploration of whether mental health nurses practice in accordance with The Family
}

\section{Model}

\begin{abstract}
Background: The Family Model is increasingly used as a framework to promote a whole family approaches in mental health services. The purpose of this qualitative study was to (i) explore whether nurses practice in accordance with the Model when providing services for parents who have mental illness, (ii) determine whether components of the model are employed more in some workplaces (i.e. acute in-patient units versus community settings) and iii) ascertain reasons as to why this may be the case.
\end{abstract}

Method: A purposive sample of 14 nurses from eight mental health services in Ireland, completed semi-structured interviews.

Results: Findings indicated that nurses' practice incorporated most key components of The Family Model, including supporting service users' dependent children. However, some practices were not explicit in the Model, such as supporting other adult family members (i.e. grandparents). While nurses' practice in community settings was more aligned with The Family Model than in acute in-patient units, there was a notable absence of reference to domain six (cultural considerations) in both settings. A holistic and family-centered philosophy, coupled with collegial and managerial support and a focus on prevention were the main features that enabled family focused practice in community settings.

Conclusion: As only a subgroup of nurses practice in accordance with The Family Model, efforts are required by nurses, their organisations and the broader system to promote family focused practice. The Family Model may be a useful framework, with further refinement, for guiding nurses' practice. 
Key Words: family focused practice, mental health services, mental health nurse, parent mental illness, The Family Model,

\section{Introduction}

Parental mental illness (PMI) is a global public health issue. Internationally, it has been estimated that between a fifth and a third of adults receiving treatment from mental health services have dependent children and that over $20 \%$ of children live with at least one parent with a mental illness (blinded et al. 2009). Within the United Kingdom (UK), Northern Ireland has the highest levels of maternal mental illness, with 53\% of children over 16 having a mother diagnosed with a common (eg. depression and/or anxiety) or severe mental illness (eg. psychosis) (Abel et al. 2019). The symptoms of mental illness can reduce a parents' capacity to parent, with adverse effects for children's well-being, including their cognitive, emotional, social, physical and behavioural development (Jacobs et al. 2015; Kallnader et al. 2018). Furthermore, stress associated with parenting may adversely affect parental mental health (blinded et al. 2018a). Accordingly, there is a need to support parents who have a mental illness in their parenting role and to address the needs of their dependent children and other family members (Foster et al. 2018).

There is increasing evidence that family focused practice (FFP) can improve outcomes for these families (Beardslee et al. 2012; Foster et al. 2016; Siegenthaler et al. 2012) and professionals, including nurses in adult mental health services, are increasingly urged to adopt a whole of family approach (blinded et al. 2018a; blinded et al. 2018b; blineded et al. 2019a).

Embedding FFP within services requires a framework to guide leadership, service reform and associated practices (blinded et al. 2019; blinded et al. 2016). A number of models have been developed to guide FFP (e.g blinded 1998; 2012; Goodman and Gotlib 1999; Hosman et al. 2009; Nicholson and Henry 2003; Nicholson et al. 2015; Wright and 
Bell 2009; Wright and Leahey 2013). The Family Model (TFM) (blinded, 2012) has been chosen for the purpose of this study because of its explicit emphasis on, and illustration of, the reciprocal nature of parents' mental illness and children's well-being, a core feature of family relationships (Beardslee et al. 2012; blinded et al. 2017). By highlighting the link between parenthood and parental mental illness, there is recognition in the Model that children's wellbeing can be promoted by supporting their parents and vice versa.

The Family Model consists of a visual illustration of six key areas (domains) and interconnecting arrows, which represent key inter-relationships between domains, with six overarching principles (see Figure 1).

Figure 1 around here

The six principles, which correspond broadly to the domains, illustrate how the mental health and well-being of children and adults within families, in which an adult carer/parent is mentally ill are intimately linked in at least six ways [blinded, 2012].

1. Adult/parental mental illness (domain 1) can adversely affect the development, mental health and, in some cases, the safety of children.

2. Children (domain 2), particularly those with emotional, behavioural or chronic physical difficulties, can precipitate or exacerbate mental ill-health in their parents/carers.

3. Growing up with a mentally ill parent (domain 3) can have a negative influence on the quality of that person's adjustment in adulthood, including their transition to parenthood. 
4. Adverse circumstances (such as poverty, lone parenthood, social isolation or stigma) can negatively influence both adult/parent and child mental health but resilience means that negative outcomes are not inevitable.

5. The quality of contact/engagement between individuals, families, practitioners and services is a powerful determinant of outcome for all family members.

6. The above five principles and their interactive relationships all occur within a broader social network encompassing cultural and community influences

In this systems approach to family functioning [blinded 2012], each domain affects and is affected by every other domain. Importantly the family system is explicitly linked with service systems (for adults and children). Furthermore, the emphasis is on links between domains over time with a lifespan (childhood-to-adulthood) and transgenerational approach. The importance of the family environment, community and social networks is also emphasised (see Figure 1).

The Family Model is increasingly used as a framework for implementing a whole family approach to service delivery in mental health services. For instance, assessment documentation in Northern Irish adult mental health and children's services has been refined in line with the domains of TFM (Donaghy 2014), particularly domain one, where nurses are prompted to identify children's needs related to PMI. Similarly, in other parts of the UK, the approach by the Social Care Institute for Excellence "to parental mental health and child welfare has its basis in The Family Model" (SCIE 2012, p2). The model also informed the New South Wales (NSW, in Australia) Children of Parents with a Mental Illness (COPMI) Framework Policy and the establishment of a 'minimum standards' approach in NSW adult 
mental health services (blinded 2012). However, to date, only two studies have examined use of TFM in practice. In 2018 (blinded et al), surveyed 3583 health and social care professionals in Northern Ireland to examine their use of TFM. While 868 professionals completed the survey, only $19 \%$ of the respondents $(n=173)$ were aware of TFM and even fewer $(\mathrm{n}=85,10 \%)$ had used it to guide their FFP. The authors recommended that HSC Trusts should continue to provide regular in-service training on family focused practice and TFM to all staff in adult mental health and children's services. This should include awareness raising and skills development, tailored to the specific needs of different staff groups. Blinded et al. (2019) also used a survey to examine the use of the model within Child and Adolescent Mental Health Services in Australia. Family members perceived its use facilitated an improvement in general communication and better shared understanding of the parent and child/young person's problems. Clinicians perceived that it helped them in developing a better understanding of family relationships, the challenges faced and a family focused care plan. As the sample size was small, (32 family members and 6 clinicians), the authors suggested that further research is required to demonstrate feasibility and clinical utility of TFM in larger samples and different settings and professional disciplines.

Notwithstanding a policy expectation for nurses to engage in FFP in Ireland, it is not known if nurses' practice reflects the TFM approach. It is also of interest to ascertain whether components of the Model are employed more by nurses' practicing in community mental health nursing services than acute in-patient admission units. The study aims were to explore (i) in what way, if any, does mental health nurses' practice reflect the domains of TFM, (ii) whether community mental health nurses' practice is more aligned with TFM than nurses' practice in acute in-patient settings, and (iii) why this may be the case. 


\section{Methods}

\section{Research Design}

The study design was predominately qualitative. As this is the first study to specifically investigate whether mental health nurses practice in accordance with TFM when caring for parents who have mental illness, it was important to allow them to fully describe their experience. In phase one, questionnaire quantitative data were collected to identify participants who were family focused (high scores on at least three of the six FFP behavioural subscales in the Family Focused Mental Health Practice Questionnaire [FFMHPQ]) (blinded et al 2012). On this basis, subsequent qualitative data were obtained from semi-structured interviews to explore how, if at all, participants' practice reflected TFM and whether components of the Model were employed more in community mental health nursing services than acute in-patient admission units.

\section{Participants}

In the initial quantitative study, 610 mental health nurses in 12 Irish mental health services were surveyed (practicing within acute admission units and community mental health services), with a 57 percent response rate $(n=346)$. A third of participants $(n=109,32 \%)$ were classified as high scorers (for further details of the quantitative study please see blinded et al. 2016).

For the qualitative study, high FFP scorers were identified. The rationale used was that high scoring nurses would be more likely to be engaging in FFP than those with lower scores and thereby able to describe the broad elements of FFP, allowing for exploration of practice with components of TFM. Other inclusion criteria included having current or recent 
(within the last 12 months) experience of caring for parents who have mental illness and currently working as a registered nurse in acute in-patient units or community mental health nursing services. Participants had also indicated a willingness to be interviewed (as noted at the end of the FFMHPQ). Fourteen of the high scoring nurses agreed to an interview.

Nine of the 14 participants were female and all were parents themselves; ten worked in community and four in hospital services. Participant's ages ranged between $26-55$. Participants' length of experience as a nurse ranged between $6-35$ years with 18 years being the average duration of experience. Participants had spent between $4-18$ years in their current position with 9 years the average time. The majority had a degree $(n=6)$ or masters level $(n=6)$ qualification and had received some form of family focused training $(n=12)$ and/or child focused training $(n=10)$. While family focused training primarily equips nurses to involve and support adult family members (Coyne et al. 2013), child focused training focuses on child development and well-being and develops nurses' attitudes, knowledge and skills to engage service users' dependent children (Lauritzen et al. 2015).

\section{Procedures}

The FFMHPQ employs a seven point Likert scale (ranging from strongly disagree to strongly agree) to measure different family focused behaviours e.g. providing support to children. Psychometric information of the FFMHPQ subscales is detailed elsewhere (blinded et al. 2012) however the measure has excellent content and construct validity and generally good internal subscale reliability (blinded et al. 2012).

In-depth, semi-structured, individual interviews were conducted by the first author at participants' workplaces. Semi-structured interviews were employed on the basis of a flexible 
structure, consisting of nine open-ended questions/probes and focusing on specific aspects of participants' FFP in relation to the six domains of TFM (see Table 1). The interview schedule was informed by the existing literature, TFM and the research questions. TFM was employed as a framework to guide the collection and analysis of interview data. Using the descriptions of the 6 domains provided in TFM handbook (blinded 2012), and as outlined above, specific questions/probes that targeted one or more central aspect of each domain were developed. Subsequently, TFM domains were mapped against interview data to examine whether nurses' practice reflected those domains.

\section{Table 1 around here}

Flexibility within the study design enabled the author to vary the sequence of the questions and ask new questions in response to significant issues raised (King and Horrocks 2010). As each transcript was analysed before undertaking the next interview, the schedule was slightly changed to incorporate important areas as they arose. Interviews ranged from forty-five to ninety minutes (average one hour). With participant permission, all interviews were recorded with a digital audio recorder and subsequently transcribed verbatim by a professional transcriber. The first author checked the accuracy of transcription and made necessary corrections.

The study was approved by the relevant university committee and participants' organisations. Participants were informed of the details of the study in explanatory statements. Participants communicated their intention to undertake interviews by completing and returning the FFMHPQ. Immediately prior to commencing their interview, participants completed an informed consent form and their preferred contact details. Maintaining participants' confidentiality is often a major ethical concern of interpretive research because 
of the intimate nature of the research (King and Horrocks 2010) but was maintained through the use of pseudonyms and changing specific contextual details that could possibly reveal the identity of the participant. In addition, participants were invited to review their individual transcript and to delete any information they believed to be potentially identifiable.

\section{Analysis}

The first author analysed the data manually. Thematic content analysis was employed through a systematic method of reduction and analysis of the textual data, in order to create core constructs. An essentialist, realist perspective was employed, which focuses on participants' experiences, meanings and realities as they report it (Braun and Clarke 2006). In this approach, participants' experiences and motivations were understood in a straightforward way, because a simple, largely unidirectional relationship is assumed between meaning, experience and language (Potter and Wetherell 1987). Data were analysed first in individual transcripts and then across transcripts. Themes were generated from information provided by participants around their practice with parents who have mental illness, their children and adult family members and capacity to engage in FFP. Specifically, information that was important to the research questions and emphasized within and across interviews comprised the presenting themes.

A hybrid model developed by Fereday and Muir-Cochrane (2006), which uses well established qualitative analysis techniques and matches these to preconceived theory, informed the analytical approach. Essentially, the hybrid model incorporates thematic content analysis with an a priori code template. The analyses were conducted in four stages. Initially open coding was undertaken to assign individual codes to the data. Initial coding was inductive and identified 55 codes that were iteratively refined. A second analysis was 
then undertaken to categorise the codes into the a priori themes established from existing literature, including the Family Model Handbook (blinded 2012). In addition, the lead author identified aspects of practice or issues not raised by other participants (negative cases) and these were further explored in subsequent interviews. The lead author discussed these negative cases with a fellow researcher in regard to emerging themes. Finally, the interpretation of findings was sent to participants for verification and no further revisions were requested (member checks; King and Horrocks 2010).

The first theme captured activities and principles underpinning nurses' FFP that resonate with domains of TFM. The second theme captured key workplace factors that influenced nurses' adherence to TFM. Themes were illustrated by participants' quotations, where participants are identified by number (e.g. P1 is participant one) and setting ( $\mathrm{cmh}$ is community mental health and hosp is hospital/acute in-pt unit).

Methodological rigour was promoted by using techniques suggested by Noble and Smith (2015). Ongoing journal entries were made which reflected the lead author's interaction with the text and possible interpretive assumptions. Additionally, the first author discussed different individual transcripts cases with the third author and interpretive findings. This process revealed a high degree of similarity between both authors in terms of the emergence of themes.

\section{Results}

Participants' practice consisted of various family focused activities and beliefs that motivated their FFP and which resonated with a number of key components and principles outlined in TFM and an additional component related to supporting non parental/carer adult family 
members. Participants also discussed workplace factors that enable nurses to practice in accordance with TFM in community settings.

\section{Nurses' activities that reflect TFM domains}

In relation to domain one (D1), (adult/parental mental illness and impact of PMI on children) all participants indicated that they were aware of the potential impact that PMI could have on children. Consequently, they identified whether the service user was a parent and the number and ages of their children during their initial assessment. Participant $11(\mathrm{cmhn})$ suggested "In our nursing assessment we explore the number of children and their ages and tease out all the issues that are going on including identifying and addressing welfare and bonding issues". Also related to D1 some participants provided examples of how they helped parents deal with practical aspects of parenting in order to promote children's wellbeing. For instance, P 3 (cmhn) reported "The child had head lice and the mother wasn't doing anything about it so I went down to the house and I brought a bottle of the stuff [treatment for head lice] with me and said to the mother come on, we'll do this together".

In relation to D2, most participants also described instances when they directly supported children to cope with PMI. One community participant, at a parent's request, held a series of meetings with younger and older children to establish what they knew about their parent's mental illness and to help them understand it. For example, "the children ranged from fifteen down to four. We had a chat with them to find out what they know and see and how did they feel about their parents' mental illness" (P 1:cmhn).

Resonating with D3 (promoting family relationships), most participants $(\mathrm{n}=11)$ also supported parents in their relationships with their children. For instance, "I would talk to 
parents about parenting strategies, how to manage inappropriate behaviours" (P 6: $\mathrm{cmh})$, while P7 (acute) reported:

He [father] feels that his relationship is deteriorating with his two children. He is getting text messages that are hurtful...the children are blaming him and he doesn't know how to respond to that. So you listen to him and try to get him to see where they're coming from and that they might be confused and you also try to reassure him.

Both groups also described assisting parents to explain their illness to their children because "some of them are so afraid of shattering a child's illusions or disappointing them that they're afraid to tackle it" (P 11:cmhn). Participant 13 (acute) told parents "you need to talk to them in a manner that's equivalent to their age...don't scare the crap out of them". Some also acknowledged the needs of partners/spouses and their role in supporting them for example, "we weren't just supporting the mother. We support partners because they are taking on a lot of the caring role of the child and need support" (P 1:cmh). Differing with TFM, all participants also discussed how they engaged and empowered other adult family members (i.e. grandparents) to support the mentally ill parent and the children in the family for example, “Illness doesn't operate in isolation from families. We try to increase grandparents' awareness of the families problems as it can make a huge difference to encourage grandparents to help out" (P 14:hosp).

In comparison to those working in the acute setting, community participants adopted a more comprehensive approach in supporting parents and their children by addressing wider issues impacting on families' daily lives. Resonating with a holistic view and D4, several community participants noted the impact of economic problems on the parents' living circumstances and parenting capacity, e.g. "I go to squalor every day so see the end result of a severe enduring mental illness. We put interventions in place to prevent poverty" (P $1: \mathrm{cmh})$. 


\section{Beliefs underpinning nurses' FFP}

The theme, beliefs underpinning nurses' FFP, is perhaps best defined and understood as the inherent principles and beliefs about working with families, parents and children that nurses bring to their practice.

Various beliefs motivated and underpinned participants' FFP. Moreover, these beliefs coincided with principles underpinning TFM as previously outlined. For instance, resonating with principles related to domains one, two and three, participants described the interrelationship between parenting and mental health and children, and specifically that parenting impacts on parental mental health and vice versa. All participants acknowledged that PMI may impact on parenting capacity and children's well-being (D1, 2 \& 3). Participant 5 (cmh) indicated "Parents may find it extremely difficult to get up in the morning, to cope with the children if they're in bad form and struggle with making meals and discipline" (P 5:cmh). Alternatively, participants also recognised the stress of parenting on parents' mental health (D3 \& D1). Participant 2 ( $\mathrm{cmhn})$ reported "she was under significant stress looking after her children. Her behaviour was becoming more and more difficult to manage. I think the stress brought her psychotic illness to the fore".

Also reflecting a key principle in TFM (related to D1 \& 2), participants suggested that children could be supported by supporting their parents. For instance, "our focus is treating parents' mental illness, getting them back to how they normally function. If they can't get well they won't be able to look after their children" (P 13:hosp).

Finally, reflecting a principle related to D5, participants suggested that the nurseparent relationship was key to effectively supporting parents and their families. For example, P 11 (cmh) reported “you can't work with the parent unless you've an emotional connection 
with them" whilst others contended "my relationship with the parent is pivotal. Without it I wouldn't be able to be as forthright" (P 12:cmh).

\section{Workplace factors that enable nurses to practice in accordance with TFM}

For the theme, workplace factors that enable nurses to practice in accordance with TFM, these factors include factors integral to the workplace such as policies, procedures, co-worker factors and collegiate activities.

Participants described a number of key workplace factors that enabled practice to be in accordance with TFM in community settings as compared to acute settings. Resonating with the longitudinal perspective highlighted by TFM, community participants suggested that the opportunity to care for parents over a period of time enabled FFP as it allowed continuity of care/relationships. Participant $11(\mathrm{cmh})$ indicated "A lot of women coming to me are in their 40s. I've been with them all along when their children have been very small and some of these children are now parents" (P 11:cmh). In contrast "Short periods of hospitalisation limit nurses' capacity to learn about parents' family contexts" (P.3:hosp). Witnessing intergenerational transmission of mental illness also motivated some community participants to engage in FFP, i.e., "Over the years FFP evolved through seeing that transgenerational cycle" (P12:cmh).

Aligned with D5, the importance of a positive organisational culture was repeatedly emphasized, based on an adoption of a holistic and family-centered philosophy, for instance, P5 (cmh) suggested "Out here it's the family you build on whereas in the hospital it's the person you build on". The majority of community participants $(n=7)$ reported that collegial and managerial support enabled FFP by providing "direction and practical resources, including time, to drive out family focused services" (P8:cmh). Conversely, "In acute in-pt 
units it is left up to each nurse to use their own initiative to support service users in their parenting role and to find time to do it" (P13:hosp).

A focus on prevention in community services also enabled FFP, akin to D5 and its underlying principle regarding the quality of contact/ engagement between individuals, families and nurses. For instance, "If we can avert difficulties in parenting, that's where we have a role. We're doing a lot of health promotion" (P1:cmh). In contrast, "There is a tendency in acute units to only think about parenting when there is a suspected child protection issue" (P4:hosp).

\section{Discussion}

The Family Model is increasingly used as a framework to embed FFP within services. However, it is not yet known whether and how nurses' practice is aligned with the TFM, nor if the model is employed more in some services and why this may be the case. The practices of the Irish high scoring nurses interviewed here were, for the most part, reflected in the TFM. Participants identified the parenting status of service users and engaged and supported service users and their dependent children (D1 \& D2). They facilitated conversations between parents and children to promote a shared understanding of parental symptoms and diagnosis (D1, D2, D3), and addressed the interplay between families' strengths and vulnerabilities (D4). Participants described behaviours and attitudes associated with good practice (e.g. openness, empathy, honesty) and a commitment to recovery and prevention (D5). Furthermore, they adhered to most of the TFM core principles by indicating an awareness of, and capacity to target relationships and the interplay of factors between the different domains, e.g., the impact of parental symptoms on children (D1 to D2) and assisting children, not just parents. Participants described the impact of children on parental mental 
health (D2 to D1) and provided examples of supporting parents to cope with parenting challenges. They argued that supporting parents not only promoted parents' recovery but enabled parents to act as a catalyst of change in their whole family. Moreover, by enhancing parenting capacity, parents' mental health could also be improved. The bidirectional interaction indicates use of, or adherence to, TFM principles 1, 2 and 3.

Participants from community settings were more likely to practice in accordance with TFM domains than participants based in hospitals. Both blinded et al (2018) and Slack and Webber (2008) found that that nurses in community settings were more family focused than those based in hospitals.

The study highlights those factors, aligned with D5, that promoted FFP in community settings, namely a positive organisational culture, (holistic and family-centered philosophy), collegial and managerial support and a focus on prevention primarily. These findings resonate with FFP enablers found in other countries such as Ireland (blinded et al. 2020), Northern Ireland (blinded et al. 2018) Australia (blinded et al.2016) and Norway (2015). Moreover, the need for long term, multifaceted implementation strategies across all services, particularly in acute in-patient settings was emphasized. Likewise, the need for broad policy shifts and organisational changes has been recommended by many around the world, in order to better identify and support these families (blinded et al 2015; blinded et al. 2017).

Most of those interviewed had received either child and/or family focused training. Others have also highlighted the importance of ongoing professional education when promoting FFP (blinded et al. 2015; Lauritzen et al., 2015; blinded et al., 2016). In Ireland, undergraduate and post registration FFP educational programmes are needed, as occurs in Finland and Norway (Lauritzen et al. 2015). Nurses' responses also suggest that the TFM 
framework might be incorporated not only in professional development programs but also supervision, consultation and collaborative work with service users and their families.

Shifting participants' attitudes, knowledge and skills to engage in FFP was likely influenced by the need to reduce the intergenerational transmission of mental illness, as others have also found (blinded et al. 2018; blinded et al. 2017), Moreover, the study underscores the need to assume a lifespan, developmental stance when working with families. Such a stance is particularly important in hospital settings where short periods of hospitalisation were identified by participants as a barrier to developing relationships with service users and subsequently, FFP. As rapport between nurses and families are key to promoting family recovery (blinded et al. 2018), the TFM might assist nurses based in hospital settings to engage with service users and their families and to capitalise on the brief time they are in contact with them.

The results also add value to the TFM as a tool which supports FFP. For example, participants described involving and supporting other adult family members (non-siblings, non-partners), who are not explicitly named in the TFM. They described how they encouraged and facilitated grandparents and aunts to support parents coping with PMI and how they might look after their own mental health. Others have pointed out the needs of other adults in these families (blinded et al. 2018c) and the key role they play in supporting parents and their children (Bland and Foster 2012). Thus, adult famly members are an integral component in a whole of family approach (Coyne et al. 2013).

Of note is that cultural considerations (D6) were not a central feature of the practice described by any of the participants here. This is concerning given that ethnic groups make up approximately 15 percent of the population of Ireland (Central Statistics Office 2012) and cultural diversity is increasingly identified as an important issue in the Irish healthcare sector 
(NCCRI and Irish Health Services Management Institute 2002). All participants were born in Ireland and were of Anglo Saxon descent, which might explain this result. Nonetheless, the results suggest the need to emphasise cultural factors in training and use of TFM, as well as ensuring a broad definition of 'family' to include key persons beyond the immediate nuclear family group.

As TFM is increasingly used in health and social care services internationally, it is also important to examine its use across different mental health and social care settings and with different professional disciplines. In addition, although a lack of formal evaluation of TFM has not diminished its appeal and integration in health and social care services over the past ten years, rigorous and systematic examination will help to broaden implementation potential. Hence, future research could explore the utility of the model in supporting FFP at the clinician/consumer/family and service design/delivery level, in both adult mental health and children's services internationally. Such initiatives might seek multiple perspectives of nurses' FFP including service users and family members.

Those interviewed were female and were parents. On average, high scoring nurses had acquired 18 years of experience, and nine of these years were obtained in the current position. These factors may have an important influence on FFP, irrespective of which particular setting the nurse is practicing in (Korhonen et al. 2010) and could be considered in future service delivery. For instance, nurses with more professional and life experience (including own parenting experience) might be encouraged and facilitated to support other colleagues with less experience.

This study had several limitations. It should be noted that the data represents mental health nurses' self-reports, which may not reflect practice. This information could be augmented by multiple perspectives of nurses' FFP, including those of managers and most 
importantly, parents who have mental illness, their children and families (including partners and grandparents). Moreover, this study represents the views of 14 mental health nurses who were classified as being family focused and who were willing to be interviewed; this may or may not be generalizable to others, including those high scoring nurses who declined to be interviewed. Nonetheless, qualitative research aims to present an in-depth understanding of a phenomenon and accordingly, is often centered on the how and why of a particular issue, process or situation (Dworkin 2012). Qualitative research, such as that employed in this study, is not concerned with generalizing to a larger population of interest and is instead inductive and emergent in its process. Hence, the aim of the in-depth interviews was to create "categories from the data and then to analyse relationships between categories" while attempting to understand the "lived experience" of the participants (Charmaz 1990, p. 1162). While it is acknowledged that the sample size of the two groups is small and uneven, it does allow us to distinguish conceptual categories across the two groups, that can then be tested in larger sample sizes in the future. Moreover, participant responses were largely consistent and met the standard of saturation for both groups; suggesting that the sample size was sufficient for the purpose of the study. Further research might explore low scoring nurses' FFP and whether other mental health professionals (i.e. psychiatrists, social workers) practice in line with the model. Observational research might also be conducted regarding whether and in what way nurses' practice reflects TFM.

In conclusion, as TFM is increasingly used to guide FFP in various health care settings internationally it is important to explore whether nursing practice reflects it. For the most part, nurses' FFP embodied many components of a whole family approach, as exemplified by the TFM, as well as the need for incorporating family members beyond the immediate, nuclear family group. This information can be used to inform further development of the Model. Parallels between nurses' FFP and TFM also highlight its utility 
in informing organisational culture, training and workforce development in FFP, particularly in hospital settings where practice is less aligned with TFM than in community settings.

\section{Acknowledgements.}

We would like to thank the mental health nurses involved in the study and their managers for facilitating access to them.

\section{Funding.}

This research did not receive any specific grant from funding agencies in the public, commercial, or not-for-profit sectors. 


\section{References}

Abel, KM; Hope, H; Swift, E; Parisi, R; Ashcroft, D.M; Kosidou, K; Osam, C.S; Dalman, C., \& Pierce, M. (2019). Prevalence of maternal mental illness among children and adolescents in the UK between 2005 and 2017: A national retrospective cohort analysis. Lancet Public Health, 4: e291-300. www.thelancet.com/public-health

Beardslee, W. R., Solantaus, T. S., Morgan, B. S., Gladstone, T. R., \& Kowalenko, N. M. (2012). Preventive interventions for children of parents with depression: International perspectives. Medical Journal of Australia Open, 1(Suppl 1), 23-25. doi: $10.5694 / \mathrm{mjao} 11.11289$

Bland, R., \& Foster, M. J. (2012). Families and mental illness: Contested perspectives and implications for practice and policy. Australian Social Work, 65, 517-534. doi: 10.1080/0312407X.2011.646281

Braun, V., \& Clarke, V. (2006). Using thematic analysis in psychology. Qualitative Research in Psychology, 3, 77-101. doi:10:1191/11478088706qp063oa

Central Statistics Office. (2012). Republic of Ireland census. This is Ireland. Highlights from Census 2011, Part One. Dublin: Government of Ireland. Available from: http://www.cso.ie/en/media/csoie/census/documents/census2011pdr/Census,2011,Hig hlights,Part,1,web,72dpi.pdf.(Accessed 10 July 2018).

Charmaz, K. (1990). 'Discovering' chronic illness: Using grounded theory. Social Science and Medicine, 30, 1161-1172.

Coyne, I., Murphy, M., Costello, T., O'Neill, C., \& Donnellan, C. (2013). A survey of nurses' practices and perceptions of family-centered care in Ireland. Journal of Family Nursing, 19, 469-488. doi: 10.1177/1074840713508224 
Donaghy, M (2014). Think Family Northern Ireland. Barnardos Childlinks, Issue 2, pp.19-

25. Available from: http://www.slideshare.net/BarnardosIreland/2014-barnardospatientsparentspeople (Accessed 13 September 2018).

Dworkin, S.L. (2012). Sample size policy for qualitative studies using in-depth interviews. Arch Sex Behav 41, 1319-1320 https://doi.org/10.1007/s10508-012-00166

Blinded. (2012).

Blinded. (1998).

Fereday, J., \& Muir-Cochrane, E. (2006). Demonstrating rigor using thematic analysis: A hybrid approach of inductive and deductive coding and theme development. International Journal of Qualitative Methods, 5, 80-92. Retrieved January 4, 2017, from http://ejournals.library. ualberta.ca/index.php/IJQM/article/view/4411/3530Blinded et al., (2018).

Blinded et al., (2018).

Blinded et al., (2016).

Blinded et al., (2019).

Blinded et al., (2017).

Blinded et al., (2015).

Goodman, S \& Gotlib, I (1999). Risks for psychopathology in the children of depressed mothers: A developmental model for understanding mechanisms of transmission. Psychological Review, 106 , 458-490.

Blinded et al., (2019a).

Houlihan, D., Sharek, D., \& Higgins, A. (2013) . Supporting children whose parent has a mental health problem: An assessment of the education, knowledge, confidence and 
practices of registered psychiatric nurses in Ireland. Journal of Psychiatric and Mental Health Nursing, 20, 287-295. doi: 10.1111/j.1365-2850.2012.01923.x

Hosman, C. M. H., van Doesum, K. T. M., \& van Santvoort, F. (2009). Prevention of emotional problems and psychiatric risks in children of parents with a mental illness in the Netherlands: I. The scientific basis to a comprehensive approach. Australian eJournal for the Advancement of Mental Health, 8, 250-263.

Blinded et al., (2019a).

Jacobs, R.H., Talati, A., Wickramaratne, P., \& Warner, V. (2015). The influence of paternal and maternal major depressive disorder on offspring psychiatric disorders. Journal of Child and Family Studies, 24, 2345-2351. doi: 10.1007/s10826-014-0037-y

Kallander, K.K., Weimand, B.M., Ruud, T., Van Roy, B., Becker, S., Hanssen-Bauer, K. (2018). Children with ill parents; extent and nature of caring activities. Scandinavian Journal of Caring Sciences. doi: 10.1111/scs.12510

King, N., \& Horrocks, C. (2010). Interviews in Qualitative Research (1st ed.). London: Sage. Korhonen, T., Vehviläinen-Julkunen, K., \& Pietilä, A. (2010) Do nurses support the patient in his or her role as a parent in adult psychiatry? A survey of mental health nurses in Finland. Archives of Psychiatric Nursing, 24, 155-167. Available from: http//dx.doi.org/10.1016/1.apnu.2008.12.002 (Accessed 12 January 2016).

Lauritzen, C Reedtz , C; Van Doesum, K \& Martinussen, M. (2015). Factors that may facilitate or hinder a family-focus in the treatment of parents with a mental illness. Journal of Child and Family Studies, 24, 864-871. doi: 10.1007/s10826-013-3985-y

Blinded et al., (2020).

Blinded et al., (2018).

Blinded et al., (2018).

Blinded et al., (2016). 
Blinded et al., (2012).

Blinded et al., (2009).

NCCRI \& Irish Health Services Management Institute. (2002). Cultural Diversity in the Irish Health Care Sector: Towards the Development of Policy and Practice. Guidelines for Organizations in the Health Care Sector. Dublin: NCCRI. Available at http://www.nccri.ie/pdf/health_services.pdf.(Accessed 11 August 2018).

Nicholson, J., Wolf, T., Wilder, C. \& Beibel, K. (2015). Creating Options for Family Recovery: A Provider's Guide to Promoting Parental Mental Health. Marlborough, MA: Employment Options Inc. Available from: URL:www.wmploymentoptions.org (Accessed 9 September 2018).

Nicholson, J., \& Henry, A. D. (2003). Achieving the goal of evidence-based psychiatric rehabilitation practices for mothers with mental illnesses. Psychiatric Rehabilitation Journal, 27, 122-130. doi: 10.2975/27.2003.122.130

Potter, J., \& Wetherell, M. (1987). Discourse and Social Psychology:Beyond Attitudes and Behaviour. London: Sage.

Blinded et al., (2019).

Slack, K., \& Webber, M. (2008). Do we care? Adult mental health professionals' attitudes towards supporting service users' children. Child \& Family Social Work, 13(1), 72-79. doi: 10.1111/j.1365-2206.2007.00516.x

Social Care Institute for Excellence. (2012). Think Child, Think Parent, Think Family: A Guide to Parental Mental Health and Child Welfare. London: Social Care Institute for Excellence (SCIE). Available from: http://www.scie.org.uk/publications/guides/guide30/files/guide30.pdf. (Accessed 8 September 2018).

Blinded et al., (2020). 
Siegenthaler, E., Munder, T. \& Egger, M. (2012). Effect of preventive interventions in mentally ill parents on the mental health of the offspring: Systematic review and meta-analysis. Journal of the American Academy of Child and Adolescent Psychiatry, 51(1), 8-17.e18.

Blinded et al., (2017).

Wright, L.M \& Leahey, M. (2013). Nurses and Families: A Guide to Family Assessment and Intervention. $6^{\text {th }}$ Ed. Philadelphia: F.A. Davis.

Wright, L.M \& Bell, J.M. (2009). Beliefs and Illness: A Model for Healing. Calgary, Canada: $4^{\text {th }}$ Floor Press. 
Table 1

Link between domains of The Family Model and focus of inquiry in interviews

\section{Domains of Family Model}

1 Adult/parental mental illness can adversely affect

the development, mental health and in some cases, the

safety of children (an adult/parent - to-child

influence).

\section{Areas of focus}

How, if at all, do you think a

parent's mental illness could impact on their parenting? And their children's well-being?

How, if at all, do you decide to become involved with service users' children? Can you tell me more about that and what your involvement entails?

How, if at all, may being a parent impact on a parent's mental illness? What is your role, if any, in supporting parents in these potentially negative interactions?
3 Growing up with a mentally ill parent can have a negative influence on the quality of that person's adjustment in childhood and in adulthood, including their transition to parenthood (a childhood-toparenthood family lifespan influence).
How, if at all, do you promote family communication between parents who have mental illness, their children and adult family members 
4 Adverse circumstances (such as poverty, lone parenthood, social isolation or stigma) can negatively influence both adult/parent and child mental health and generate resilience (an environment-to-family influence).

5 The quality of contact/engagement between individuals, families, practitioners and services is a powerful determinant of outcome for all family members (a service-to-family influence).
How, it at all, do you reduce families' risk factors and stressors?

How, if at all, do you promote their strengths?

Tell me about your capacity to engage in FFP, with parents, who have mental illness, their children and adult family members.

What factors enable and/or hinder nurses' capacity to support parents who have mental illness, their children and families?

How, if at all, do you consider and address families' cultural and wider social networks? broader, more distal, environment-to-family influence). 
Figure 1: Falkov (2012) The Family Model

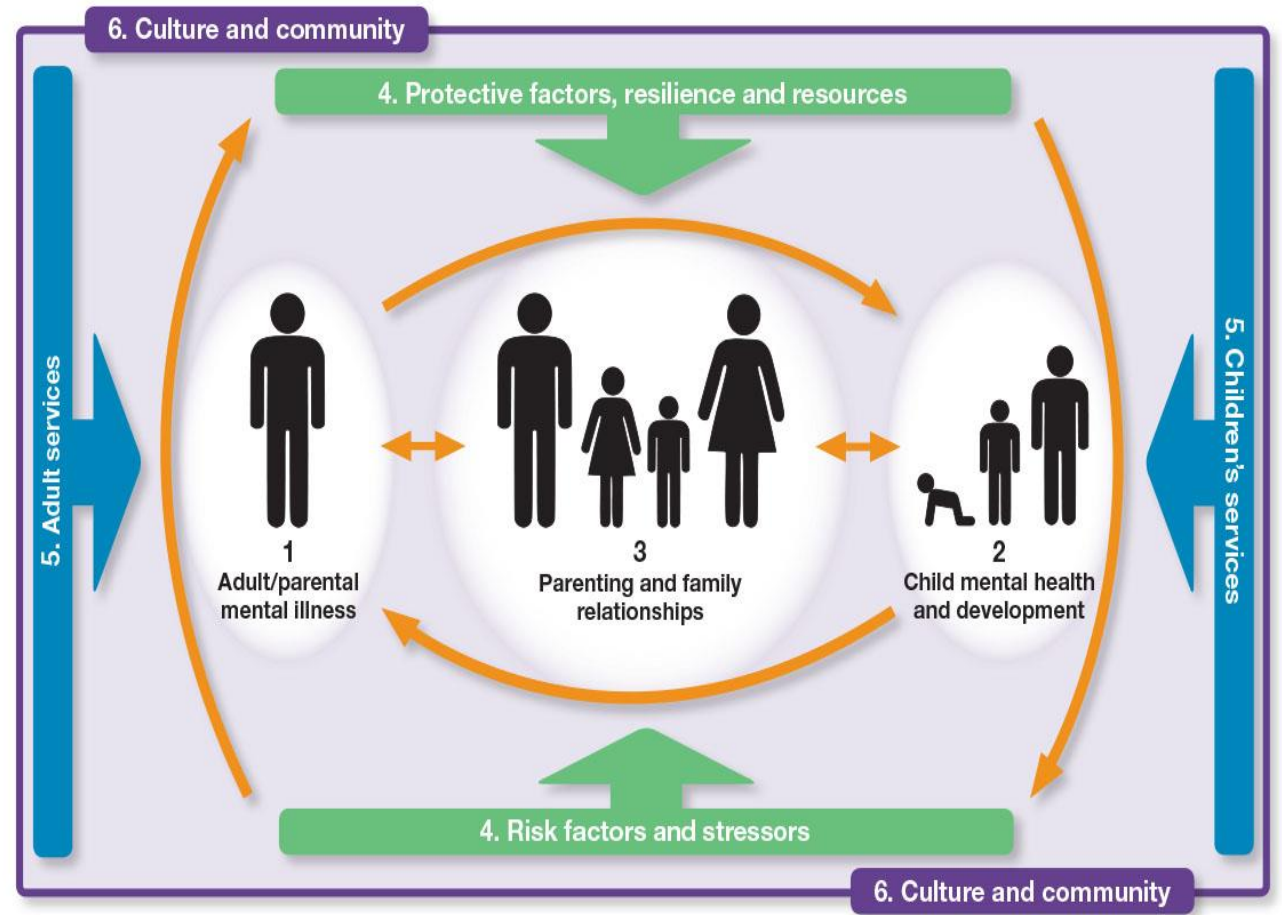

